\title{
Maternal Dietary Alpine Butter Intake Affects Human Milk: Fatty Acids and Conjugated Linoleic Acid Isomers
}

\author{
Isabelle Bertschi ${ }^{a}$, Marius Collomb $^{b}$, Lukas Rist $^{c}$, Pius Eberhard ${ }^{b}$, Robert Sieber ${ }^{b}$, \\ Ulrich Bütikofer $^{b}$, Daniel Wechsler ${ }^{b}$, Gerd Folkers ${ }^{d}$, and Ursula von Mandach ${ }^{a, *}$ \\ ${ }^{a}$ Department of Obstetrics, Zurich University Hospital, CH-8091 Zurich, ${ }^{b}$ Agroscope Liebefeld-Posieux, Swiss Federal \\ Research Station for Animal Production and Dairy Products (ALP), CH-3003 Berne, ${ }^{C}$ Paracelsus Hospital, CH-8805 \\ Richterswil, and Institute of Pharmaceutical Sciences, Swiss Federal Institute of Technology Zurich, CH-8092 Zurich, Switzerland
}

\begin{abstract}
Consumption of CLA by lactating women affects the composition of their milk, but the pattern of the different CLA isomers is still unknown. We determined the effects of short maternal supplementation with CLA-rich Alpine butter on the occurrence of FA and CLA isomers in human milk. In an open randomized controlled study with a two-period cross-over design, milk FA and CLA isomer concentrations were measured on postpartum days $\geq 20$ in two parallel groups of lactating women before, during, and after consumption of defined quantities of Alpine butter or margarine with comparable fat content $(10 \mathrm{~d}$ of butter followed by $10 \mathrm{~d}$ of margarine for one group, and vice versa in the other). In the 16 women who completed the study (8/group), Alpine butter supplementation increased the $C_{16}$ and $C_{18} F A$, the sum of saturated FA, the $18: 1$ trans $F A$, and the trans FA with CLA. The CLA isomer 18:2 $c 9, t 11$ increased by $49.7 \%$. Significant increases were also found for the isomers $t 9, t 11, t 7, c 9, t 11, c 13$, and $t 8, c 10$ 18:2. The remaining nine of the total 14 detectable isomers showed no changes, and concentrations were $<5 \mathrm{mg} / 100 \mathrm{~g}$ fat. A breastfeeding mother can therefore modulate the FA/CLA supply of her child by consuming Alpine butter. Further studies will show whether human milk containing this FA and CLA isomer pattern acts as a functional food for newborns.

Paper no. L9632 in Lipids 40, 581-587 (June 2005).
\end{abstract}

Human milk (from German women) contains more longchain FA, with chain lengths of $\mathrm{C}_{20}$ to $\mathrm{C}_{24}$ including several double bonds, than bovine milk fat. It contains a high proportion of palmitic acid $(16: 0,25.3 \%)$ and the isomeric groups of 18:1 and 18:2, their main components being oleic acid ( $c 9$, $29.0 \%)$ and linoleic acid $(c 9, c 12,9.5 \%)(8)$.

The major CLA isomer is $c 9, t 11$-octadecadienoic acid $(c 9, t 11$ 18:2) (1), also called rumenic acid (2). Although linoleic acid is isom-erized by the enzymatic conversion of the $c 12$ to the $t 11$ bond by the anaerobe Butyrivibrio fibrisolvens in the rumen (3), an estimated $64 \%$ of dairy milk fat CLA is of endogenous origin (4). Total CLA and isomer concentrations in dairy milk fat depend on feeding (i.e., pasture, oilseeds), the effects of altitude and season, as well as the age and breed of the cow (5-7). Total CLA and isomer concentrations in human milk depend on maternal diet, stage of lactation, and de novo synthesis (8-12). As humans

\footnotetext{
*To whom correspondence should be addressed at Frauenklinikstrasse 10, CH-8091 Zürich, Switzerland. E-mail: ursula.vonmandach@usz.ch

Abbreviations: BMI, body mass index; CLA, conjugated linoleic acid; EFA, essential fatty acid; FA, fatty acid; GC, gas chromatograph(y).
}

do not synthesize PUFA, concentrations depend exclusively on dietary fat intake (13). A study reporting CLA concentrations $(c 9, t 11$ isomer) of $5.8 \mathrm{mg} / \mathrm{g}$ fat in milk from mothers on conventional diets vs. $11.2 \mathrm{mg} / \mathrm{g}$ fat in Hare Krishna mothers hypothesized that the difference was due to the large amounts of butter, ghee, and cheese consumed by the latter (9). Chronic dietary $c 9, t 11$ 18:2 intake is thought to increase milk 18:2 $c 9, t 11$ concentrations (10). The proportions of partially hydrogenated oils and ruminant fats in the diet also determine trans 18:1 isomeric distribution (8), whereas maternal diet, i.e.. consumption of different products or amounts of milk and meat, has been shown to correlate with differences in the CLA content of human milk (11).

Several effects of a high-CLA diet in animals and humans have been described. However, for the effect of most interest to us, that on neonatal development, only animal data are available: in rats, increased milk CLA concentrations in dams on a high-CLA diet are associated with enhanced pup weight gain (14). Recent studies have also shown that individual isomers have different effects.

The aim of the present investigation as an essential preliminary to an efficacy study was to quantify CLA isomers and FA concentrations in human milk from mothers consuming defined quantities of CLA-rich Alpine butter.

\section{SUBJECTS, MATERIALS, AND METHODS}

Subjects. Following approval from the Institutional Review Board of the Departments of Obstetrics and Urology at Zurich University Hospital, healthy lactating women $(n=20)$ from the Obstetrics Department were recruited on day (D) 2-4 postpartum with their written informed consent. The noninclusion criteria were pre-existing disease, medication other than vitamins or minerals, HIV, mastitis, vegan or similar extreme diet, substance abuse (including alcohol), smoking, and inability to understand conversational German. Subjects started the study from D20 postpartum when at home and healthy in lactation stage III.

Protocol. Dietary treatment was randomized in sealed opaque envelopes according to an open controlled two-period cross-over design in two parallel groups. Group 1 followed a normal diet at home to day 20 postpartum (= study D1). From D1 through D10 (period 1), women were invited to supplement their diet with 40 $\mathrm{g} / \mathrm{d}$ (4 packages of $10 \mathrm{~g}$ per $24 \mathrm{~h}$ ) margarine $(\mathrm{M})\left(\right.$ Becel $^{\circledR}$; 
www.unilever.com) containing $24 \mathrm{~g}$ fat and $16 \mathrm{~g}$ water. From D11 through D20 (period 2), the diet was supplemented with 30 $\mathrm{g} / \mathrm{d}$ ( 3 packages of $10 \mathrm{~g}$ per $24 \mathrm{~h}$ ) Alpine butter $(\mathrm{AB})$ containing $25.7 \mathrm{~g}$ fat, $4.3 \mathrm{~g}$ water, and an average of $2.09 \mathrm{~g} \mathrm{CLA} / 100 \mathrm{~g}$ milk fat (equivalent to approximately $0.5 \mathrm{~g} \mathrm{CLA} / \mathrm{d}$ ). The difference between the daily amount of M (30 g) and AB (40 g), respectively, should result in an equal daily fat intake from the study products. Group 2 women followed the same dietary schedule in reverse order (period 1: $\mathrm{AB}$; period 2: $\mathrm{M}$ ).

The Alpine butter originated from Alp Mutten (Graubünden, Switzerland, $2100 \mathrm{~m}$ altitude) and consisted of a blend of five $2-\mathrm{kg}$ portions that was produced between July 1 and 25, 2003 , and stored at $-20^{\circ} \mathrm{C}$ until use. The 10 -g portions of this blend contained $8.6 \mathrm{~g}$ fat, $1.4 \mathrm{~g}$ water, and $180.0 \mathrm{mg}$ total CLA (corresponding to $2.09 \mathrm{~g}$ total CLA/100 g milk fat). The predominant CLA isomers were $c 9, t 11, t 11, c 13, t 7, c 9$, and $t 8, c 10$ 18:2. The FA and CLA composition of the two supplements is shown in Table 1.

The women had to record the real daily intake of study products (weight). No additional Alpine milk or ruminant meat products were allowed during the study.

Dietary diary. The subjects documented potential additional sources of CLA by recording every day the estimated intake (volume or weight) of milk and dairy products (yogurt, sour cream, cream, cheese, etc.) and meat (type). The amount of a consumed product was given in the database of the EBIS program (15), which transforms the consumed volume or weight of a product in consumed grams fat by considering the product's specific percent fat. From the daily fat intake, the daily CLA intake (milligrams) was calculated using the values of Fritsche and Steinhart $(16,17)$ for CLA amounts (grams CLA per gram fat) in different foods (German and others); for chicken or turkey the CLA values of Chin et al. (1) were used.

Milk sampling. On D1, D5, D10, D15, and D20, the subjects took milk samples at home according to a standardized procedure assisted by the principal investigator (IB): between 8:00 and 11:00 A.M. and 1-3 $\mathrm{h}$ after a continental breakfast, the breast that was not actually used for infant feeding at the last feed was emptied completely using an electric pump (Lacti$\mathrm{na}^{\mathrm{TM}}$ Electric plus; Medela AG, Baar, Switzerland) and the volume measured; $2 \times 10$-mL aliquots were transferred to plastic tubes, cooled at $+4^{\circ} \mathrm{C}$ (cold box), and stored at $-20^{\circ} \mathrm{C}$ until analysis. The remainder was fed to the baby.

Lipid extraction and analysis of FA. (i) Lipid extraction. Milk fat was obtained gravimetrically using the Roese-Gottlieb method, i.e., the fat globule membranes were disrupted with ammonia and ethanol, the fat was extracted with diethyl ether and petroleum ether, and the pure fat was stored at $-20^{\circ} \mathrm{C}$ until analysis (18).

(ii) FA. The milk fat was dissolved in hexane, and the glycerides were transesterified to the corresponding FAME using a solution of potassium hydroxide in methanol $(2 \mathrm{~mol} / \mathrm{L})$ as per ISO standard 15885. FA composition was determined using a gas chromatograph (GC; Agilent 6890, www.agilent.com) equipped with an on-column injector and FID (19). Nearly 70 FA were separated on a capillary column $(100 \mathrm{~m} \times 0.25 \mathrm{~mm} \times$
TABLE 1

Fatty Acids and CLA Isomers in Margarine and Alpine Butter

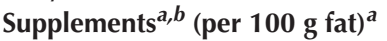

\begin{tabular}{|c|c|c|c|}
\hline FA & Unit & Margarine & Alpine butter \\
\hline $14: 0$ & $\mathrm{~g}$ & 0.83 & 6.99 \\
\hline $15: 0$ & g & 0.02 & 1.29 \\
\hline $16: 0$ & $g$ & 10.83 & 19.88 \\
\hline $17: 0$ & g & 0.04 & 0.78 \\
\hline 18:0 & g & 3.75 & 11.25 \\
\hline $18: 1 c 9$ & $\mathrm{~g}$ & 24.24 & 20.55 \\
\hline $18: 1 t 6-8$ & $\mathrm{~g}$ & $<0.01$ & 0.16 \\
\hline $18: 1 t 9$ & $\mathrm{~g}$ & $<0.01$ & 0.28 \\
\hline $18: 1 t 12$ & $g$ & $<0.01$ & 0.18 \\
\hline $18: 1 t 13-14+c 6-8$ & g & 0.01 & 0.62 \\
\hline $18: 2 c 9, c 12$ & $\mathrm{~g}$ & 46.70 & 1.53 \\
\hline $18: 2 t 7, c 9+t 8, c 10+c 9, t 11$ & g & $<0.01$ & 1.85 \\
\hline $18: 2 c 9, c 11+t 9, t 11+t 11, c 13$ & g & $<0.01$ & 0.14 \\
\hline $18: 2 t 12, t 14$ & $\mathrm{mg}$ & ND & 20.4 \\
\hline $18: 2 t 11, t 13$ & $\mathrm{mg}$ & ND & 33.2 \\
\hline $18: 2 t 10, t 12$ & mg & ND & 2.8 \\
\hline $18: 2 t 9, t 11$ & mg & ND & 15.0 \\
\hline $18: 2 t 8, t 10$ & mg & ND & 1.7 \\
\hline $18: 2 t 7, t 9$ & $\mathrm{mg}$ & ND & 10.2 \\
\hline $18: 2 t 6, t 8$ & $\mathrm{mg}$ & ND & 4.7 \\
\hline $18: 2 c / t 12,14$ & mg & ND & 5.3 \\
\hline $18: 2 t 11, c 13$ & mg & ND & 148.2 \\
\hline $18: 2 c 11, t 13$ & mg & ND & 3.4 \\
\hline $18: 2 t 10, c 12$ & mg & ND & 1.6 \\
\hline $18: 2 c 9, t 11$ & $\mathrm{mg}$ & ND & 1767.3 \\
\hline $18: 2 t 8, c 10$ & mg & ND & 29.5 \\
\hline $18: 2 t 7, c 9$ & $\mathrm{mg}$ & ND & 49.0 \\
\hline $18: 3 c 9, c 12, c 15$ & $g$ & 0.12 & 1.24 \\
\hline Saturated $\mathrm{FA}^{c}$ & g & 18.97 & 51.80 \\
\hline Monounsaturated $\mathrm{FA}^{d}$ & g & 25.41 & 29.87 \\
\hline PUFA $^{e}$ & g & 47.72 & 6.72 \\
\hline 18:1 trans $^{f}$ & $\mathrm{~g}$ & 0.03 & 5.94 \\
\hline$\Sigma 18: 2$ & g & 47.34 & 5.03 \\
\hline $18: 2$ trans without trans $\mathrm{CLA}^{g}$ & $\begin{array}{l}8 \\
g\end{array}$ & 0.08 & 1.45 \\
\hline 18:2 trans with $\mathrm{CLA}^{h}$ & $\mathrm{~g}$ & 0.09 & 3.31 \\
\hline trans $\mathrm{FA}$ without $\mathrm{CLA}^{i}$ & g & 0.11 & 7.72 \\
\hline trans $\mathrm{FA}$ with $\mathrm{CLA}^{j}$ & g & 0.12 & 9.59 \\
\hline $\mathrm{n}-3^{k}$ & g & 0.93 & 2.22 \\
\hline$n-6^{l}$ & g & 46.79 & 2.38 \\
\hline
\end{tabular}

${ }^{a}$ Values are means, $n=3$.

${ }^{b}$ A selected summation of FA that addresses specific points to the discussion is presented. CLA isomers were analyzed by silver-ion HPLC and are ordered according to their retention time; ND, not detectable; $t$ NMID, trans, trans non-methylene interrupted diene; ccMID, cis,cis methylene interrupted diene.

${ }^{c} \mathrm{AB}: 4: 0,5: 0,6: 0,7: 0,8: 0,10: 0,12: 0,12: 0$ iso, $12: 0$ aiso, 13:0 iso, 14:0, 14:0 iso, 14:0 aiso, 15:0, 15:0 iso, 16:0, 16:0 iso, 16:0 aiso, 17:0, 17:0 iso, 17:0 aiso, 18:0, 19:0, 20:0, 22:0; M: 8:0, 10:0, 12:0, 14:0, 15:0, 16:0, 16:0 aiso, 17:0, 17:0 aiso, 18:0, 20:0, 22:0, 24:0.

${ }^{d} \mathrm{AB}: 10: 1,14: 1 c t, 16: 1 c t, 17: 1 c t, 18: 1-t 4,-t 5,-t 6-8,-t 9,-t 10-11,-t 12$, $-(t 13-14+c 6-8), 20: 1 \quad t, 20: 1 \quad c 5,20: 1 \quad c 9,20: 1 \quad c 11 ; M: 16: 1 \quad c, 18: 1$ $-t 10,-c 9,-c 11,20: 1 c 11$

${ }^{e} \mathrm{AB}: 18: 2$ [ $\Sigma t t \mathrm{NMID}, t 9, t 12, c 9, t 13+(t 8, c 12), c 9, t 12+(c c \mathrm{MID}+t 8, c 13), t 11, c 15$ $+t 9, c 12),-c 9, c 12,-c 9, c 15,18: 3-c 6, c 9, c 12,-c 9, c 12, c 15,18: 2-(c 9, t 11+-t 8, c 10$ $+-t 7, c 9),-(t 11, c 13+-c 9, c 11),-t 9, t 11,20: 2 c c \mathrm{n}-6,20: 3 \mathrm{n}-6,20: 3 \mathrm{n}-3,20: 4 \mathrm{n}-6$, 20:5n-3, 22:5n-3, 22:6n-3; M: 18:2 -(c9,t12 + ccMID + -t8,c13), -(t11,c15 + $t 9, c 12],-c 9, c 12,-c 9, c 15,18: 3 c 9, c 12, c 15,20: 3 \mathrm{n}-3,20: 4 \mathrm{n}-6,20: 5 \mathrm{n}-3$.

${ }^{f} \mathrm{AB}: 18: 1 t 4$ to $t 13-14 ; \mathrm{M}: 18: 1-t 10$.

${ }^{g} \mathrm{AB}: 18: 2$ trans $[\Sigma t t \mathrm{NMID}, t 9, t 12, c 9, t 13+(t 8, c 12), c 9, t 12+(c c \mathrm{MID}+, t 8 c 13$, $t 11, c 15+t 9, c 12] ; M: 18: 2-(c 9, t 12+t 8, c 13),-(t 11, c 15+t 9, c 12)$.

${ }^{h} \mathrm{AB}: 18: 2 t+\mathrm{CLA}$ trans $(\Sigma \mathrm{C} 18: 2 t 7, c 9, t 8, c 10, c 9, t 11, t 9, t 11, t 11, c 13)$; $\mathrm{M}: 18: 2-(c 9, t 12+t 8, c 13),-(t 11, c 15+t 9, c 12)$.

${ }^{i} \mathrm{AB}: 14: 1 t, 16: 1 t, 17: 1 t, 20: 1 t, 18: 1$ trans and 18:2 trans (without CLA trans $) ; \mathrm{M}: 18: 1 t 10,18: 2-(c 9, t 12+t 8, c 13),-(t 11, c 15+t 9, c 12)$.

${ }^{j} \mathrm{AB}: 14: 1 t, 16: 1 t, 17: 1 t, 20: 1 t, 18: 1$ trans, $18: 2$ trans and CLA trans; M: $18: 1 t 10,18: 2-(c 9, t 12+t 8, c 13),-(t 11, c 15+t 9, c 12)$.

${ }^{k} \mathrm{AB}: 18: 2-c 9, c 15+-t 11, c 15,18: 3 c 9, c 12, c 15,20: 3,20: 5,22: 5,22: 6 ; \mathrm{M}:$ $18: 2-c 9, c 15,-t 11, c 15,18: 3 c 9, c 12 c 15,20: 3,20: 5$.

${ }^{l} \mathrm{AB}: 18: 1-t 12,-c 12,18: 2-t 9, t 12,-c 9, t 12,-c 9, c 12,18: 3 c 6, c 9, c 12,20: 2 c c$ 20:3, 20:4; M: 18:2 -c9,t12, -c9,c12, 20:3, 20:4. 


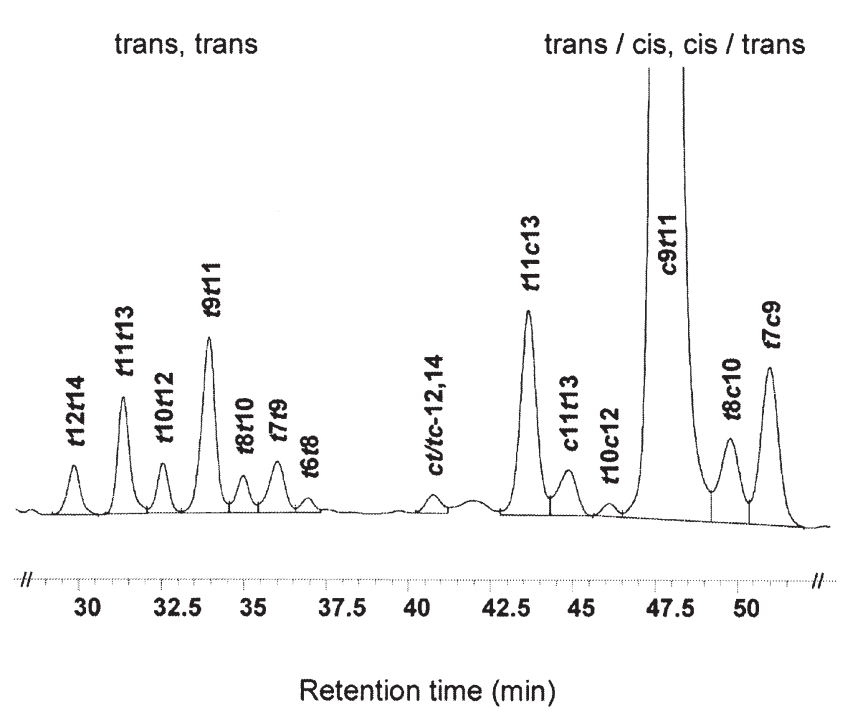

FIG. 1. Silver-ion HPLC $\left(\mathrm{Ag}^{+}-\mathrm{HPLC}\right)$ separation of CLA methyl esters of human milk using three columns in series (peak $t 6, t 8$ tentatively assigned according to Ref. 20).

$0.20 \mu \mathrm{m}, \mathrm{CP}-\mathrm{Sil}$ 88; www.varianinc.com) and quantified in absolute values (g FA/100 g fat) using nonanoic acid as internal standard.

(iii) CLA isomers. CLA isomers were analyzed by silver-ion $\left(\mathrm{Ag}^{+}\right)$HPLC according to Rickert et al. (20), modified by Kraft et al. (21). The analysis was performed on an Agilent LC series 1100 equipped with a photodiode array detector (234 nm) using three ChromSpher Lipids columns in series (stainless steel, 250 $\times 4.6 \mathrm{~mm}, 5 \mu \mathrm{m}$ particle size; Chrompack, Middleburg, The Netherlands). The solvent consisted of UV-grade hexane with $0.1 \%$ acetonitrile and $0.5 \%$ ethyl ether (flow rate $1 \mathrm{~mL} \mathrm{~min}^{-1}$ ), prepared fresh daily. Injection volumes were $10 \mu \mathrm{L}$, representing $<250 \mu \mathrm{g}$ lipid. The identification of CLA isomers was based on co-injection with commercial reference material and synthesized CLA. The methyl esters of $c 9, t 11$ (98\%), $t 10, c 12$ (98\%), and $c 9, t 11$ 18:2 (75-78\%) were obtained from Matreya Inc. (Pleasant Gap, PA). Other CLA isomers were synthesized by isomerization of the commercially available reference (technical grade) with $\mathrm{I}_{2}(22)$. The results were expressed as absolute values in $\mathrm{mg}$ per $100 \mathrm{~g}$ fat. Fourteen different CLA isomers were separated by this HPLC method (Fig. 1).

Statistical analysis. A power calculation was performed based on an expected difference in CLA human milk content of $30 \%$ between the two phases, Alpine butter $(\mathrm{AB})$ and margarine (M). The power was $80 \%$ for $n=8 /$ group $(\alpha=0.5)$.

Data were entered into Excel, analyzed in Systat for Windows, version 10.2 (www.uic.edu/depts/accc/software), and expressed as means \pm SD. The Kolmogorov-Smirnov test was used for normality. Mean values were compared using the unpaired two-tailed $t$-test for cross-over design and a $P$ value of $<0.05$. "Effect" refers to the differences between the two phases $\mathrm{AB}$ vs. M of group-pooled data, and "period" to the period effect, i.e., the differences between the two phases $A B$ and $M$ of group 1 vs. group 2.

\section{RESULTS}

Subjects. Three women withdrew because of lactation failure and one developed diarrhea in response to Alpine butter, leaving eight subjects per group. The groups did not differ statistically in age ( $27.8 \pm 3.5$ vs. $29.5 \pm 5.6 \mathrm{yr}$, respectively), parity, gravidity, gestational age at delivery, or body mass index (BMI) during the study (Table 2).

Two group 2 women were excluded from the statistical analysis of the CLA isomers because of technical problems in the isomer analysis.

Study product intake and dietary diaries (Table 3). The mean daily intake of margarine was $29.75 \mathrm{~g}$ (group 1) and $30.25 \mathrm{~g}$ (group 2) and that of Alpine butter $22.0 \mathrm{~g}$ (group 1) and $23.75 \mathrm{~g}$ (group 2). Study product intake was thus below the requested level (margarine: up to $40.0 \mathrm{~g}$; Alpine butter: up to 30.0 $\mathrm{g})$. The higher intake of margarine than butter $(P=0.003)$ resulted in an equal daily fat intake in both groups $(P=0.25$ differences between $\mathrm{M}$ and $\mathrm{AB}$ [effect] and differences between the groups [period]). Fat intake was calculated from $60 \mathrm{~g}$ fat/100 $\mathrm{g}$ (margarine) and $85.8 \mathrm{~g}$ fat/100 $\mathrm{g}$ (Alpine butter) as specified in the Subjects, Materials, and Methods section.

Dietary nonsupplement CLA intake, calculated from the daily dietary records, also did not differ statistically $(P=0.52)$ between phases or groups. Extremely small or zero amounts of ruminant meat (beef) were recorded in both groups, as requested (data not shown).

Human milk. (i) Fat content. In neither group did fat content of human milk differ significantly between margarine and butter phases (group 1: $3.3 \pm 0.6$ vs. $3.4 \pm 1.6 \mathrm{~g} / 100 \mathrm{~mL}$ milk; group 2: $2.9 \pm 1.3$ vs. $3.4 \pm 1.1 \mathrm{~g} / 100 \mathrm{~mL}$ milk) corresponding to a mean fat yield $(\mathrm{g})$ per breast of 1.94 in the margarine and 1.90 in the butter phase (NS).

(ii) FA. The sum of saturated FA increased by $2.057 \mathrm{~g} / 100$ $\mathrm{g}$ fat during the pooled butter phases $(P=0.03), 18: 1$ trans FA by $0.428 \mathrm{~g} / 100 \mathrm{~g}$ fat $(P=0.001)$, and trans FA with CLA by $0.178 \mathrm{~g} / 100 \mathrm{~g}$ fat $(P=0.005)$ (all without period effects). There were significant pooled-group decreases in the butter phases in the sum of PUFA (3.502 g/100 g fat), 18:2 (3.252 $\mathrm{g} / 100 \mathrm{~g}$ fat), n-6 FA (3.571 g/100 g fat) (all $P=0.001)$, and the sum of unsaturated FA $(3.389 \mathrm{~g} / 100 \mathrm{~g}$ fat; $P=0.02)$ (Table 4). The ratio of $n-6 / n-3$ FA was lower in the butter than in the margarine phases (mean: 13.7 vs. $17.9, P<0.01$ ), but the dif-

\section{TABLE 2}

Population Demographic and Obstetric Data ${ }^{a}$

\begin{tabular}{|c|c|c|c|c|}
\hline & \multicolumn{2}{|c|}{ Group $1(n=8)$} & \multicolumn{2}{|c|}{ Group $2(n=8)$} \\
\hline & Mean & $\overline{S D}$ & Mean & $\mathrm{SD}$ \\
\hline Age $(y r)$ & 27.8 & 3.5 & 29.4 & 4.8 \\
\hline Parity (n) & 1.6 & 0.5 & 1.8 & 0.7 \\
\hline Gravidity (n) & 2.1 & 1.4 & 2.0 & 1.3 \\
\hline Gestational age (wk) at delivery & 40.6 & 1.3 & 40.1 & 1.4 \\
\hline $\mathrm{BMI}^{b}\left(\mathrm{~kg} / \mathrm{m}^{2}\right)$ & 25.0 & 2.6 & 26.5 & 6.4 \\
\hline Days postpartum at study start & 35.3 & 13.3 & 33.3 & 9.3 \\
\hline
\end{tabular}

avalues between the groups do not differ.

${ }^{b}$ Mean of the five body weight values measured on the five sampling days. $\mathrm{BMI}$, body mass index. 
TABLE 3

Documented Intake of Study Products (and corresponding fat and CLA) and Dietary CLA (pooled study days)

\begin{tabular}{|c|c|c|c|c|c|c|c|c|c|c|}
\hline & \multicolumn{4}{|c|}{ Group $1(n=8)$} & \multicolumn{4}{|c|}{ Group $2(n=8)$} & & \\
\hline & \multicolumn{2}{|c|}{$M$} & \multicolumn{2}{|c|}{$A B$} & \multicolumn{2}{|c|}{$\mathrm{AB}$} & \multicolumn{2}{|c|}{$M$} & \multicolumn{2}{|c|}{$P^{a}$} \\
\hline & Mean & SD & Mean & SD & Mean & SD & Mean & $\mathrm{SD}$ & Effect $^{b}$ & Period $^{c}$ \\
\hline \multicolumn{11}{|c|}{ Study product intake } \\
\hline Amount (g/d) & 29.75 & 10.91 & 22.00 & 7.67 & 23.75 & 6.81 & 30.25 & 8.05 & 0.003 & NS \\
\hline $\mathrm{Fat}^{d}(\mathrm{~g} / \mathrm{d})$ & 17.85 & 6.55 & 18.88 & 6.58 & 20.38 & 5.85 & 18.15 & 4.83 & NS & NS \\
\hline $\mathrm{CLA}^{e}(\mathrm{mg} / \mathrm{d})$ & $<2$ & & 379.4 & 132.3 & 409.6 & 117.6 & $<2$ & & $<0.001$ & NS \\
\hline \multicolumn{11}{|l|}{ Dietary intake } \\
\hline $\mathrm{CLA}^{\mathrm{f}^{\prime}}(\mathrm{mg} / \mathrm{d})$ & 81.1 & 79.7 & 64.9 & 52.3 & 109.7 & 104.2 & 70.9 & 63.4 & NS & NS \\
\hline
\end{tabular}

${ }^{a}$ Unpaired two-tailed $t$-test for cross-over design: NS, nonsignificant.

${ }^{b}$ Effect: overall (both groups) AB (Alpine Butter) vs. M (Margarine).

${ }^{c}$ Period: $\mathrm{AB}$ vs. $\mathrm{M}$ of group 1 vs. group 2.

${ }^{d}$ Calculated from $85.8 \mathrm{~g}$ fat/100 $\mathrm{g}(\mathrm{AB})$ and $60 \mathrm{~g}$ fat/100 $\mathrm{g}(\mathrm{M})$.

${ }^{e} \mathrm{C} 18: 2 t 7, c 9+t 8, c 10+c 9, t 11$ and $\mathrm{C} 18: 2 c 9, c 11+t 9, t 11+t 11, c 13$.

${ }^{f} \mathrm{C} 18: 2 c 9, c 11+t 9, t 11+t 11, c 13$ calculated by EBIS program (19) according to nutrition protocol.

ference was only minimal if we consider a ratio of 1 vs. 50 in the corresponding study products (see Table 1).

The butter phases showed highly significant pooled-group differences ( $\mathrm{g} / 100 \mathrm{~g}$ fat; all $P<0.001)$ vs. margarine in the following individual FA (Table 4): increases in $\mathrm{C}_{15}(0.116 \mathrm{~g}), \mathrm{C}_{16}$ $(1.507 \mathrm{~g}), \mathrm{C}_{17}(0.072 \mathrm{~g}), \mathrm{C}_{18}(0.960 \mathrm{~g})$, and $t 9, c 12+t 11, c 15$ 18:2 (0.043 g); decreases in $c 9, c 12$ 18:2 (3.632 g), $c, c 20: 2 \mathrm{n}-6$ (0.056 g), and 20:3n-6 (0.062 g) FA.

CLA isomers. (i) At baseline. The overall baseline concentration (D1, after normal nonstandardized diet, $n=14$ ) showed a predominance of the $c 9, t 11(277 \pm 195 \mathrm{mg} / 100 \mathrm{~g}$ fat, range $77-800), t 9, t 11(13 \pm 7 \mathrm{mg} / 100 \mathrm{~g}$ fat, range 4-31), and $t 11, c 13$ (12 $\pm 10 \mathrm{mg} / 100 \mathrm{~g}$ fat, range 2-37) 18:2 isomers, and a total CLA concentration of $352 \pm 229 \mathrm{mg} / 100 \mathrm{~g}$ fat (range 103-956).

(ii) During the study. Analysis of the mean pooled study day values (D5 + D10 and D15 + D20, respectively), showed significant increases in $t 12, t 14, t 11, t 13, t 6, t 8, c 11, t 13, t 11, c 13$, $c 9, t 11$, and $t 8, c 1018: 2$ as well as in the sum of CLA isomers during Alpine butter intake of both groups (Table 4). There were no significant period effects. Pooled-group increases of the individual isomers, expressed per $100 \mathrm{~g}$ fat, are shown in Figure 2. The sum of CLA isomers increased by $129.4 \mathrm{mg}$ (45.0\%, $P=0.005)$ and the ratio of $t 11, c 13$ and $t 7, c 918: 2$ isomers by $70.8 \%(P<0.0001)$.

\section{DISCUSSION}

This study demonstrated that $10-\mathrm{d}$ supplementation with Alpine butter, a natural CLA-rich product, affects the FA and CLA isomer content of human milk.

Butter significantly increased the concentrations of saturated FA. At study start (after a normal nonstandardized diet), 18 $c 9, t 1118: 2$ and total CLA concentrations in human milk were $277 \pm 195$ (range 7-800) and $352 \pm 229$ (range 103-956) $\mathrm{mg} / 100 \mathrm{~g}$ fat, respectively. The isomers showing the highest increases in milk were $t 11, c 13(100.5 \%), t 6, t 8(67.3 \%), t 12, t 14$ (61.3\%), c9,t11 (49.7\%), c11,t13 (39.6\%), t11,t13 (34.0\%), and $t 8, c 10(28.2 \%)($ all $P<0.05)$.
Ethical limitations in standardization and compliance, which was not $100 \%$ in our study (Table 3), make human data inevitably more variable than their dairy counterparts. The women were allowed to consume their total supplement per 24 $\mathrm{h}$ in as many portions as they wished, and we could not control for the well-known differences in absorption relating to the amount of fat per portion (23). However, our study has certain advantages compared with others with human milk $(9,10)$. The cross-over design excluded interindividual differences and differences due to lactation duration; all subjects consumed the same supplements with defined fat content and FA composition; milk sampling was standardized (volume, time of day) to minimize the effect of differential fat absorption (23) and milk volume (24); dietary intake of other dairy and beef products was recorded daily throughout the study; BMI was calculated throughout; milk analysis was longitudinal, with two time points per period. Since no significant differences were found in compliance, BMI, dietary (nonsupplement) CLA intake, or total milk fat content between periods or groups, these factors can be excluded as accounting for the differential milk content of FA or CLA isomers in response to butter supplementation.

Our basal value in human milk for the predominant isomer $(c 9, t 11$ 18:2) $(0.25 \mathrm{~g} / 100 \mathrm{~g}$ fat $)$ is similar to those reported by Jensen et al. (0.19 and $0.18 \mathrm{~g} / 100 \mathrm{~g}$ fat) $(25,26)$, Park et al. (0.21 g/100 g fat) (10), and Ritzenthaler et al. $(0.28 \mathrm{~g} / 100 \mathrm{~g}$ total FA) (12) in lactating American mothers during the lowdairy periods $(10,25,26)$ or in baseline (12). However, McGuire et al. (27) and Innis and King (28) recorded higher basal values $(0.4 \mathrm{~g} / 100 \mathrm{~g}$ fat $)$ in American mothers, matching those in German mothers (0.39 and $0.40 \mathrm{~g} / 100 \mathrm{~g}$ fat) (29).

The increase in the predominant $c 9, t 11$ isomer in our study by $109.8 \mathrm{mg} / 100 \mathrm{~g}$ fat $(49.7 \%)$ approximates that reported by Park et al. (10) (64.6\%) from the low to the high CLA dairy period of their study and is higher than that reported by Ritzenthaler et al. (12) (29.0\%) from baseline to 4 wk of consumption of high-CLA cheese. Unlike us, earlier investigators into human milk CLA content could identify, in addition to the predominant $c 9, t 11 \quad 18: 2$ isomer, only $t 9, t 11$ (29), $t 10, c 12$ $(12,27,29), t 7, c 9$ (30), and $t 9, t 11 / t 10, t 12$ 18:2 (12). In milk 
TABLE 4

FA and CLA Isomers in Human Milk (per $100 \mathrm{~g}$ human milk fat) During Maternal Supplementation with Margarine and Alpine Butter (pooled study days)

\begin{tabular}{|c|c|c|c|c|c|c|c|c|c|c|c|}
\hline \multirow[b]{3}{*}{$\mathrm{FA}^{a}$} & \multicolumn{5}{|c|}{ Group $1(n=8)$} & \multicolumn{4}{|c|}{ Group $2\left(n=8^{b}\right)$} & \multirow{2}{*}{\multicolumn{2}{|c|}{$P^{c}$}} \\
\hline & \multicolumn{3}{|c|}{$M$} & \multicolumn{2}{|c|}{$\mathrm{AB}$} & \multicolumn{2}{|c|}{$\mathrm{AB}$} & \multicolumn{2}{|c|}{$M$} & & \\
\hline & Unit & Mean & SD & Mean & SD & Mean & SD & Mean & SD & $\mathrm{Effect}^{d}$ & Period $^{e}$ \\
\hline $14: 0$ & $\mathrm{~g}$ & 5.13 & 0.73 & 5.66 & 1.06 & 5.99 & 1.38 & 5.67 & 1.18 & NS & NS \\
\hline $15: 0$ & g & 0.31 & 0.05 & 0.42 & 0.07 & 0.49 & 0.13 & 0.37 & 0.13 & $<0.001$ & NS \\
\hline $16: 0$ & g & 20.28 & 1.96 & 20.62 & 2.14 & 22.22 & 2.87 & 19.55 & 3.45 & $<0.001$ & $<0.05$ \\
\hline $17: 0$ & g & 0.29 & 0.04 & 0.36 & 0.06 & 0.39 & 0.08 & 0.32 & 0.09 & $<0.001$ & NS \\
\hline 18:0 & $\mathrm{g}$ & 6.04 & 1.05 & 6.83 & 1.16 & 7.38 & 1.04 & 6.25 & 1.05 & $<0.001$ & NS \\
\hline $18: 1 c 9$ & $\mathrm{~g}$ & 26.38 & 3.19 & 26.16 & 3.75 & 26.91 & 3.54 & 27.02 & 3.50 & NS & NS \\
\hline $18: 1$ t9 & $\mathrm{g}$ & 0.30 & 0.11 & 0.28 & 0.14 & 0.27 & 0.07 & 0.27 & 0.12 & NS & NS \\
\hline $18: 2 c 9, c 12$ & g & 14.64 & 3.60 & 12.41 & 6.06 & 7.96 & 2.72 & 13.00 & 2.99 & $<0.001$ & NS \\
\hline $18: 2 t 12, t 14$ & $\mathrm{mg}$ & 1.46 & 0.62 & 2.90 & 1.56 & 2.77 & 1.90 & 2.06 & 0.92 & 0.007 & NS \\
\hline $18: 2 t 11, t 13$ & $\mathrm{mg}$ & 4.18 & 1.57 & 6.83 & 2.24 & 6.43 & 4.07 & 5.72 & 1.90 & 0.03 & NS \\
\hline $18: 2 t 10, t 12$ & $\mathrm{mg}$ & 2.49 & 0.99 & 3.71 & 1.63 & 2.40 & 0.78 & 3.17 & 0.34 & NS & NS \\
\hline $18: 2 t 9, t 11$ & $\mathrm{mg}$ & 14.8 & 12.9 & 19.4 & 14.8 & 13.4 & 11.8 & 14.6 & 11.7 & NS & NS \\
\hline $18: 2 t 8, t 10$ & $\mathrm{mg}$ & 3.21 & 0.61 & 3.21 & 1.27 & 2.96 & 1.50 & 2.88 & 0.72 & NS & NS \\
\hline $18: 2 t 7, t 9$ & $\mathrm{mg}$ & 4.01 & 1.25 & 4.35 & 1.16 & 4.40 & 1.35 & 4.45 & 0.92 & NS & NS \\
\hline $18: 2 t 6, t 8$ & $\mathrm{mg}$ & 0.46 & 0.16 & 0.90 & 0.34 & 0.83 & 0.23 & 0.58 & 0.22 & 0.002 & NS \\
\hline $18: 2 \mathrm{ct} / \mathrm{tc} 12,14$ & $\mathrm{mg}$ & 0.86 & 0.50 & 1.22 & 0.56 & 1.15 & 0.64 & 0.98 & 0.35 & NS & NS \\
\hline $18: 2 t 11, c 13$ & $\mathrm{mg}$ & 6.2 & 3.1 & 15.6 & 6.1 & 17.1 & 10.9 & 10.1 & 5.0 & 0.001 & NS \\
\hline $18: 2 c 11, t 13$ & $\mathrm{mg}$ & 3.26 & 1.19 & 5.14 & 2.16 & 5.99 & 3.13 & 4.71 & 1.69 & 0.02 & NS \\
\hline $18: 2 t 10, c 12$ & $\mathrm{mg}$ & 1.31 & 1.07 & 1.94 & 1.58 & 0.90 & 0.27 & 1.44 & 0.59 & NS & NS \\
\hline $18: 2 c 9, t 11$ & $\mathrm{mg}$ & 176.0 & 75.6 & 309.5 & 120.7 & 351.6 & 212.0 & 265.6 & 114.7 & 0.005 & NS \\
\hline $18: 2 t 8, c 10$ & $\mathrm{mg}$ & 6.6 & 1.8 & 9.6 & 3.8 & 10.7 & 5.4 & 9.2 & 2.5 & 0.04 & NS \\
\hline $18: 2 t 7, c 9$ & $\mathrm{mg}$ & 10.4 & 4.0 & 13.7 & 6.0 & 16.0 & 7.1 & 14.9 & 4.3 & NS & NS \\
\hline$\Sigma C L A$ & $\mathrm{mg}$ & 235.2 & 87.0 & 397.9 & 141.7 & 436.6 & 248.6 & 340.5 & 126.8 & 0.005 & NS \\
\hline $18: 3 c 9, c 12, c 15$ & $\mathrm{~g}$ & 0.44 & 0.21 & 0.41 & 0.08 & 0.38 & 0.16 & 0.50 & 0.19 & NS & NS \\
\hline $20: 3 n-6$ & $\mathrm{~g}$ & 0.31 & 0.09 & 0.26 & 0.09 & 0.21 & 0.12 & 0.29 & 0.11 & $<0.001$ & NS \\
\hline $20: 4 n-6$ & $g$ & 0.32 & 0.12 & 0.29 & 0.12 & 0.19 & 0.09 & 0.26 & 0.06 & $<0.01$ & NS \\
\hline Saturated $\mathrm{FA}^{f}$ & g & 37.27 & 1.84 & 40.64 & 4.13 & 38.77 & 3.96 & 38.03 & 3.84 & $<0.05$ & NS \\
\hline Monounsaturated FA ${ }^{g}$ & $\mathrm{~g}$ & 30.11 & 4.17 & 31.57 & 5.01 & 30.17 & 6.49 & 31.36 & 4.17 & NS & NS \\
\hline PUFA $^{h}$ & g & 16.28 & 4.17 & 14.77 & 6.30 & 9.35 & 3.64 & 14.84 & 3.43 & $<0.001$ & $<0.05$ \\
\hline 18:1 trans $^{i}$ & $\mathrm{~g}$ & 1.31 & 0.21 & 1.85 & 0.49 & 1.72 & 0.56 & 1.40 & 0.52 & $<0.001$ & NS \\
\hline$\Sigma 18: 2$ & $g$ & 14.69 & 3.69 & 13.30 & 6.10 & 8.19 & 3.20 & 13.30 & 3.14 & $<0.001$ & $<0.05$ \\
\hline trans $\mathrm{FA}$ with $\mathrm{CLA}^{j}$ & $\mathrm{~g}$ & 2.04 & 0.32 & 2.91 & 0.67 & 2.62 & 0.93 & 2.26 & 0.73 & $<0.001$ & NS \\
\hline $\mathrm{n}-6^{k} / \mathrm{n}-3^{l}$ & & 19.8 & 5.21 & 15.38 & 6.64 & 11.95 & 3.33 & 15.98 & 3.52 & $<0.01$ & NS \\
\hline
\end{tabular}

${ }^{a}$ CLA isomers and CLA were analyzed by silver-ion HPLC and are ordered according to their retention time.

$b_{n}=6$ for CLA isomers.

${ }^{c}$ Unpaired two-tailed $t$-test for cross-over design: NS, nonsignificant.

${ }^{d}$ Effect: overall (both groups) AB (Alpine Butter) vs. M (Margarine).

${ }^{e}$ Period: $\mathrm{AB}$ vs. $\mathrm{M}$ of group 1 vs. group 2.

${ }^{f}$ For footnote $f$ see Table 1, footnote $c$.

${ }^{g}$ For footnote $g$ see Table 1 , footnote $d$.

${ }^{h}$ For footnote $h$ see Table 1 , footnote $e$.

${ }^{i}$ For footnote $i$ see Table 1, footnote $f$.

${ }^{j}$ For footnote $j$ see Table 1 , footnote $j$.

${ }^{k}$ For footnote $k$ see Table 1 , footnote $l$.

${ }^{l}$ For footnote $l$ see Table 1, footnote $k$.

from German women, $c 9, t 11$ 18:2 accounted for no more than $0.39 \%, t 9, t 1118: 2$ at most $0.04 \%$, and $t 10, c 1218: 2$ at most $0.08 \%$ of total FA (29). For Yurawecz et al. (30), the $t 7, c 918: 2$ isomer accounted for 5.5-9.9\% of total CLA. In our study, the $c 9, t 11, t 9, t 11, t 7, c 9$, and $t 10, c 12$ isomers accounted for 0.380 , $0.019,0.018$, and $0.002 \%$ of total FA and for $79,3.9,3.6$, and $0.3 \%$ of total CLA; these values are consistent with those indicated above.

The distribution of other FA in milk during the study periods reflects some but not all of the differences between supplements (Table 1). The 18:1 trans FA other than trans10-11, which occur in low concentrations in both study products, also show low concentrations in human milk during both phases. This aspect could be of interest because in recent years attention has been given to the potential impairment of EFA metabolism to their long-chain metabolites by the trans-isomers in humans (31). It is therefore unlikely that the small amounts found in human milk in our study have any important negative effect on the newborn. The higher amounts of $\mathrm{C}_{15}, \mathrm{C}_{16}, \mathrm{C}_{17}$, and $\mathrm{C}_{18}$ acids and the trans unsaturated octadecadienoic acids $(t 9, c 12+t 11, c 1518: 2)$ are likely to have resulted from their higher content in Alpine butter. $\mathrm{C}_{15}$ and $\mathrm{C}_{17}$ acids are synthe- 


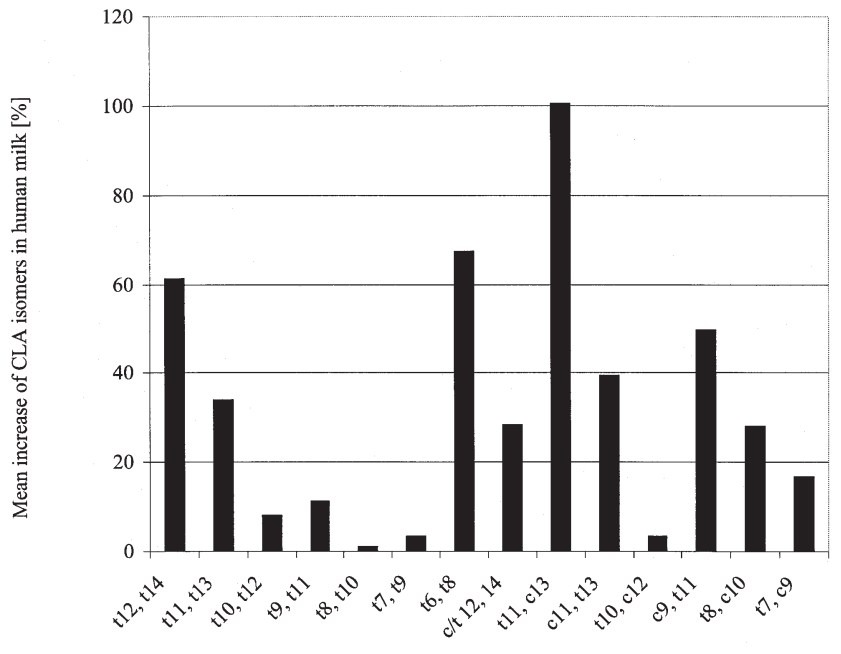

FIG. 2. Mean increase (\%) of CLA isomers in human milk during pooled Alpine butter intake $(n=14)$.

sized by ruminant flora but not in humans owing to the uneven number of carbon atoms (32). They thus act as markers of a dairy fat diet $(33,34)$. The highly significant decrease $(3.63$ $\mathrm{g} / 100 \mathrm{~g}$ milk fat $=26.3 \%)$ in octadecadienoic acid $(c 9, c 12$ 18:2) on butter vs. margarine is also probably due to its much lower content in butter than in margarine (1.53 g vs. 46.70 $\mathrm{g} / 100 \mathrm{~g}$ fat). The $\mathrm{n}-6 \mathrm{FA}$ that occur at high concentrations in margarine have an extremely low transfer into human milk.

Mothers can rapidly and easy modulate the fat composition of their milk by consuming Alpine butter (or related natural dairy products). This could have positive implications for the newborn. Several studies, most of them in animals, have indicated the potential impact of CLA-rich milk on the development of the newborn. One point could be the potential effect on body weight. In rats, the $c 9, t 1118: 2$ isomer increases body weight $(14,35)$, whereas the $t 10, c 1218: 2$ isomer decreases it in both mice $(35,36)$ and humans [loss of body fat in diabetics (37)]. Another point could be the protection of CLA-rich milk against development of atopy. In rats and mice, oral supplementation with $100 \mathrm{mg} / \mathrm{kg}$ CLA (isomer profile unknown) reduces allergic anaphylaxis (by decreasing blood pressure), vasodilatation, and scratching behavior in response to egg-white lysozyme (38). However, further studies in humans are necessary to confirm these effects and to show whether human milk with a special pattern of FA and CLA could be a functional food for newborns.

\section{ACKNOWLEDGMENT}

The authors would like to very sincerely thank the women and infants who participated in this study.

\section{REFERENCES}

1. Chin, S.F., Liu, W., Storkson, J.M., Ha, Y.L., and Pariza, M.W. (1992) Dietary Sources of Conjugated Dienoic Isomers of Linoleic Acid, a Newly Recognized Class of Anticarcinogens, J. Food Comp. Anal. 5, 185-197.

2. Kramer, J.K.G., Parodi, P.W., Jensen, R.G., Mossoba, M.M.,
Yurawecz, M.P., and Adlof, R.O. (1998) Rumenic Acid: A Proposed Common Name for the Major Conjugated Linoleic Acid Isomer Found in Natural Products, Lipids 33, 835.

3. Kepler, C.R., Hirons, K.P., McNeill, J.J., and Tove, S.B. (1966) Intermediates and Products of the Biohydrogenation of Linoleic Acid by Butyrivibrio fibrisolvens, J. Biol. Chem. 241, 1350-1354.

4. Griinari, J.M., Corl, B.A., Lacy, S.H., Chouinard, P.Y., Nurmela, K.V.V., and Bauman, D.E. (2000) Conjugated Linoleic Acid Is Synthesized Endogenously in Lactating Dairy Cows by $\Delta^{9}$-Desaturase, J. Nutr. 130, 2285-2291.

5. Lawless, F., Stanton, C., L'Escop, P., Devery, R., Dillon, P., and Murphy, J.J. (1999) Influence of Breed on Bovine Milk $c 9, t 11$ Conjugated Linoleic Acid Content, Livestock Prod. Sci. 62, 43-49.

6. Lawless, F., Murphy, J.J., Harrington, D., Devery, R., and Stanton, C. (1998) Elevation of Conjugated cis-9, trans-11-Octadecadienoic Acid in Bovine Milk Because of Dietary Supplementation, J. Dairy Sci. 81, 3259-3267.

7. Collomb, M., Bütikofer, U., Sieber, R., Jeangros, B., and Bosset, J.O. (2002) Composition of Fatty Acids in Cow's Milk Fat Produced in the Lowlands, Mountains and Highlands of Switzerland Using High-Resolution Gas Chromatography, Int. Dairy J. 12, 649-659.

8. Precht, D., and Molkentin, J. (1999) C18:1, C18:2 and C18:3 trans and cis Fatty Acid Isomers Including Conjugated cis $\Delta 9$,trans $\Delta 11$ Linoleic Acid (CLA) as Well as Total Fat Composition of German Human Milk Lipids, Nahrung 43, 233-244.

9. Fogerty, A.C., Ford, G.L., and Svoronos, D. (1988) Octadeca9,11-dienoic Acid in Foodstuffs and in the Lipids of Human Blood and Breast Milk, Nutr. Rep. Int. 38, 937-944.

10. Park, Y., McGuire, M.K., Behr, R., McGuire, M.A., Evans, M.A., and Shultz, T.D. (1999) High-Fat Dairy Product Consumption Increases $\Delta 9 c, 11 t$-18:2 (rumenic acid) and Total Lipid Concentrations of Human Milk, Lipids 34, 543-549.

11. Rist, L., Zweidler, R., and von Mandach, U. (2003) Biologische Ernährung und Gesundheit [Biological Diet and Health (German)], in Ökologischer Landbau der Zukunft [Prospects in Organic Farming (German)] (Freyer, B., ed.), pp. 237-240, Universität für Bodenkultur, Institut für Ökologischen Landbau/Institute for Organic Farming, Vienna,.

12. Ritzenthaler, K.L., McGuire, M.K., McGuire, M.A., Shultz, T.D., Koepp, A.E., Luedecke, L.O., Hanson, T.W., Dasgupta, N., and Chew, B.P. (2005) Consumption of Conjugated Linoleic Acid (CLA) from CLA-Enriched Cheese Does Not Alter Milk Fat or Immunity in Lactating Women, J. Nutr. 135, 422-430.

13. Francois, C.A., Connor, S.L., Wander, R.C., and Connor, W.E. (1998) Acute Effects of Dietary Fatty Acids on the Fatty Acids of Human Milk, Am. J. Clin. Nutr. 67, 301-308.

14. Chin, S.F., Storkson, J.M., Liu, W., Albright, K.J., and Pariza, M.W. (1994) Conjugated Linoleic Acid (9,11- and 10,12-octadecadienoic acid) Is Produced in Conventional but Not GermFree Rats Fed Linoleic Acid, J. Nutr. 124, 694-701.

15. Erhardt, J., and Bosch, R. (1995) Programm und Handbuch zur Ernährungsanamnese: EBIS; Ernährungsanamnese, Beratungsund Informationssystem auf der Grundlage des Bundeslebensmittelschlüssels (BLS) [Dietary history programme and handbook: EBIS (Dietary History-Counselling and Information System Based on the German Food Code [BLS]). Stuttgart Hospital and University of Hohenheim.

16. Fritsche. J., and Steinhart, H. (1998) Amounts of Conjugated Linoleic Acid in German Foods and Evaluation of Daily Intake, Z. Lebensm. Unters. Forsch. 201, 77-82.

17. Fritsche, J., and Steinhart, H. (1998) Analysis, Occurrence and Physiological Properties of trans Fatty Acids with Particular Emphasis on Conjugated Linoleic Acid Isomers, Fett/Lipid 100, 190-210. 
18. Collomb, M., Sieber, R., and Bütikofer, U. (2004) CLA Isomers in Milk Fat from Cows Fed Diets with High Levels of Unsaturated Fatty Acids, Lipids 39, 355-364.

19. Collomb, M., and Bühler, T. (2000) Analyse de la Composition en Acides Gras de la Graisse de Lait. I. Optimisation et Validation d'une Méthode Générale à Haute Résolution [Analysis of the Fatty Acid Composition of Milk Fat, I. Optimization and Validation of a General High Resolution Method (French)], Trav. chim. aliment. hyg. 91, 306-332.

20. Rickert, R., Steinhart, H., Fritsche, J., Sehat, N., Yurawecz, M.P., Mossoba, M.M., Roach, J.A.G., Eulitz, K., Ku,Y., and Kramer, J.K.G. (1999) Enhanced Resolution of Conjugated Linoleic Acid Isomers by Tandem-Column Silver-Ion High Performance Liquid Chromatography, J. High Resolut. Chromatogr. 22, 144-148.

21. Kraft, J., Collomb, M., Möckel, P., Sieber, R., and Jahreis, G. (2003) Differences in CLA Isomer Distribution of Cow's Milk Lipids, Lipids 38, 657-664.

22. Eulitz, K., Yurawecz, M.P., Sehat, N., Fritsche, J., Roach, J.A.G., Mossoba, M.M., Kramer, J.K.G., Adlof, R.O., and Ku, Y. (1999) Preparation, Separation, and Confirmation of the Eight Geometrical cis/trans Conjugated Linoleic Acid Isomers 8,10- through 11,13-18:2, Lipids 34, 873-877.

23. Ramirez, M., Amate, L., and Gil, A. (2001) Absorption and Distribution of Dietary Fatty Acids from Different Sources, Early Hum. Dev. 65, S95-S101.

24. Mitoulas, R.L., Gurrin, L.C., Doherty, D.A., Sheriff, J.L., and Hartmann, P.E. (2003) Infant Intake of Fatty Acids from Human Milk over the First Year of Lactation, Br. J. Nutr. 90, 979-986.

25. Jensen, R.G., Lammi-Keefe, C.J., Hill, D.W., Kind, A.J., and Henderson, R. (1998) The Anticarcinogenic Conjugated Fatty Acid, $9 c, 11 t-18: 2$, in Human Milk: Confirmation of Its Presence, J. Hum. Lact. 14, 23-27.

26. Jensen, R.G., and Lammi-Keefe, C. (2001) The Anticarcinogenic Conjugated Fatty Acid $c 9, t 11-c 18: 2$, or Rumenic Acid, in Human Milk: Amounts and Effects, Adv. Exp. Med. Biol. 501, 153-156.

27. McGuire, M.K., Park, Y., Behre, R.A., Harrison, L.Y., Shultz, T.D., and McGuire, M.A. (1997) Conjugated Linoleic Acid Concentrations of Human Milk and Infant Formula, Nutr. Res. 17, 1277-1283.

28. Innis, S.M., and King, D.J. (1999) Trans Fatty Acids in Human Milk Are Inversely Associated with Concentrations of Essential all-cis n-6 and n-3 Fatty Acids and Determine trans, but not n-6 and n-3, Fatty Acids in Plasma Lipids of Breast-Fed Infants, Am. J. Clin. Nutr. 70, 383-390.

29. Jahreis, G., Fritsche, J., Möckel, P., Schone, F., Möller, U., and Steinhart, H. (1999) The Potential Anticarcinogenic Conjugated Linoleic Acid, cis-9,trans-11 C18:2, in Milk of Different Species: Cow, Goat, Ewe, Sow, Mare, Woman, Nutr. Res. 19, $1541-1549$

30. Yurawecz, M.P., Roach, J.A.G., Sehat, N., Mossoba, M.M., Kramer, J.K.G., Fritsche, J., Steinhart, H., and Ku, Y. (1998) A New Conjugated Linoleic Acid Isomer, 7 trans, 9 cis-Octadecadienoic Acid, in Cow Milk, Cheese, Beef and Human Milk and Adipose Tissue, Lipids 33, 803-809.

31. Mojska, H. (2003) Influence of trans Fatty Acids on Infant and Fetus Development, Acta Microbiol. Pol. 52, (Suppl.), 67-74.

32. Wu, Z., and Palmquist, D.L. (1991) Synthesis and Biohydrogenation of Fatty-Acids by Ruminal Microorganisms in vitro, $J$. Dairy Sci. 74, 3035-3046.

33. Smedman, A.E.M., Gustafsson, I.B., Berglund, G.T., and Vessby, B.O.H. (1999) Pentadecanoic Acid in Serum as a Marker for Intake of Milk Fat: Relations Between Intake of Milk Fat and Metabolic Risk Factors, Am. J. Clin. Nutr. 69, 22-29.

34. Wolk, A., Vessby, B., Ljung, H., and Barrefors, P. (1998) Evaluation of a Biological Marker of Dairy Fat Intake, Am. J. Clin. Nutr. 68, 291-295.

35. Pariza, M.W., Park, Y., and Cook, M.E. (2001) The Biologically Active Isomers of Conjugated Linoleic Acid, Prog. Lipid Res. 40, 283-298.

36. Loor, J.J., Lin, X.B., and Herbein, J.H. (2003) Effects of Dietary cis 9 , trans 11-18:2, trans 10, cis 12-18:2 or Vaccenic Acid (trans 11-18:1) During Lactation on Body Composition, Tissue Fatty Acid Profiles, and Litter Growth in Mice, Br. J. Nutr. 90, 1039-1048.

37. Belury, M.A., Mahon, A., and Banni, S. (2003) The Conjugated Linoleic Acid (CLA) Isomer, $t 10 c 12-C L A$, Is Inversely Associated with Changes in Body Weight and Serum Leptin in Subjects with Type 2 Diabetes Mellitus, J. Nutr. 133, 257S-260S.

38. Ishiguro, K., Oku, H., Suitani, A., and Yamamoto, Y. (2002) Effects of Conjugated Linoleic Acid on Anaphylaxis and Allergic Pruritus, Biol. Pharm. Bull. 25, 1655-1657.

[Received October 15, 2004; accepted May 23, 2005] 